\title{
An Update in the Use of JJ Stents
}

\section{Actualización en el uso de catéteres J J}

\author{
Ana María Ortiz Zableh ${ }^{1}$ Danielle Bastidas Rosas ${ }^{2}$ Hugo López Ramos ${ }^{3}$ \\ ${ }^{1}$ Semillero de investigación en urología y genética, Pontificia \\ Universidad Javeriana, Bogotá, Colombia \\ ${ }^{2}$ Estudiante de medicina, Semillero de investigación en urología y \\ genética, Pontificia Universidad Javeriana, Bogotá, Colombia \\ 3 Urológo, Hospital Universitario San Ignacio, Bogotá, Colombia \\ Address for correspondence Ana María Ortiz Zableh, MD, Semillero \\ de investigación en urología y genética, Pontificia Universidad \\ Javeriana. Carrera 22a \# 35-74, Floridablanca \\ (e-mail: Aortizz.92@gmail.com).
}

Urol Colomb 2019;28:142-148.

\section{Abstract \\ Keywords \\ - catheters \\ - ureteral stent \\ - infection \\ - ureteral obstruction \\ - vesico-ureteral reflux \\ - urolithiasis}

\section{Resumen}

Introduction Ureteral stents are widely used tools in the daily practice of the urologist due to the fact that they solve the endo- and extraluminal ureteral obstructions, enabling an adequate urine flow. They are the preferred tool because they are easy to insert and versatile, and are used to treat various urologic pathologies; nonetheless, they are not exempt from complications.

Objectives To present an update in the use of J stents, describing their main associated symptoms and complications, indications and newest developments.

Materials and Methods We performed a literature review in the Embase, Pubmed and Google Scholar databases, with the following terms and cross-references: ureteral stent; diagnosis; treatment; and urology, restricting the search to the past 7 years. A total of 428 articles were found, and 49 were used in the revision.

Results We described the symptoms and complications associated with the use of JJ stents and their prevention, their use in the treatment of lithiasis and oncologic diseases, the utility of metallic stents, and new designs and improvements in their development.

Conclusions JJ stents remain a very useful tool in the daily practice of the urologist, but are not exempt from having adverse effects and complications. There have been advances that decrease the adverse effects associated with their use, mainly infection, symptoms associated to the insertion, and risk of incrustation.

Introducción Los catéteres ureterales son una herramienta ampliamente usada en la práctica diaria del urólogo, dado a que alivian la obstrucción endo y extraluminal ureteral, permitiendo así el adecuado flujo de orina. Se prefieren por encima de otros métodos por su facilidad de inserción y su versatilidad de uso dentro de las distintas patologías urológicas; sin embargo, no están exentos de complicaciones.

Objetivos Presentar una actualización en el uso de catéteres J] que incluya información acerca de los síntomas y complicaciones, sus indicaciones de uso y novedades. Materiales y Métodos Realizamos una revisión narrativa de la literatura en las bases de datos Embase, Pubmed y Google Scholar, con los siguientes términos y sus received

May 5, 2018

accepted

June 11, 2018
DOI https://doi.org/

$10.1055 / \mathrm{s}-0038-1670646$

ISSN 0120-789X.

eISSN 2027-0119.
Copyright (c) 2019, Sociedad Colombiana License terms de Urología. Publicado por Thieme Revinter Publicações Ltda., Rio de Janeiro, Brazil. Todos los derechos reservados. 


\section{Palabras clave}

- catéteres

- stent ureteral

- infección

- obstrucción ureteral

- reflujo vesicoureteral

- urolitiasis respectivas referencias cruzadas: ureteral stent; diagnosis; treatment; y urology, restringiendo la búsqueda a los últimos siete años. Se encontraron un total de 428 artículos, de los cuales se tomaron 49 para esta revisión.

Resultados Describimos los síntomas y complicaciones asociadas con el uso de catéteres JJ, su prevención, uso en urolitiasis y enfermedades oncológicas, el uso de catéteres metálicos, y nuevos diseños y mejoras en su desarrollo.

Conclusiones Los catéteres JJ siguen siendo una herramienta muy útil en la práctica urológica diaria; sin embargo, no están exentos de tener efectos adversos y complicaciones. En la actualidad existen múltiples estrategias que pretenden mejorar su uso y seguimiento. En los últimos años ha habido avances en el desarrollo de los catéteres que se han visto reflejados en una disminución importante en los efectos adversos secundarios a su uso, principalmente infección, los síntomas asociados a la inserción, y riesgo de incrustación.

\section{Introduction}

Ureteral stents (USs) are common tools employed in Urology that enable urine drainage from the kidney to the bladder. Zimskind first described them in 1967; Gibbons introduced the auto retention US in 1976; and, subsequently, Finney described in 1978 the US known as "double J"1,2 They are frequently used in the ureteroscopic management of lithiasis, trauma, oncologic and reconstructive surgery.

Despite their wide use, they present multiple secondary effects due to the fact that they are strange bodies that induce inflammation on the urothelium. Among these effects are pain, a sensation of discomfort, urinary urgency, hematuria, associated infection and incrustation. ${ }^{3,4}$ There is no clear etiology for the inflammatory reaction that the US causes on the urothelium. ${ }^{1}$ As of today, different types of US and different biomaterials have been developed in order to decrease these adverse effects. ${ }^{5}$

The ideal US should be easy to insert, relieve the endo- or extraluminal obstruction, enable an adequate urinary flow, be resistant to incrustation and infections, be chemically stable, and should not produce associated symptoms. Therefore, it should have high tensile force, low friction coefficient, and should be self-holding. ${ }^{1,3}$ Unfortunately, we currently do not have an "ideal urinary stent."

The first designed USs were made of silicone and had an open tip, but were not self-holding. As their use increased, new forms were developed, until the development of the now used double $\mathrm{J}(\mathrm{JJ})$, which is self-holding, thus preventing distal and proximal migration, and decreasing the urinary symptoms. The associated complications can be divided into early ones (which occur less than 4 weeks after the insertion), such as dysuria, abdominal pain and hematuria, and late ones (which occur more than 4 weeks after the insertion), such as migration, obstruction, calcification, and urinary tract infection (UTI). ${ }^{6}$

The present article reviews the indications for the use of USs, describing their main associated symptoms, complications and their prevention, and the novelties regarding innovation in this field.

\section{Materials and Methods}

We performed a literature review in the Embase, Pubmed and Google Scholar databases, with the following terms and crossreferences: ureteral stent; diagnosis; treatment; and urology, restricting the search to the past 7 years. A total of 428 articles were found, and 49 were selected for this peer literary review for being the most relevant and with more novelties.

\section{Review}

\section{Symptoms}

The associated symptoms with the use of USs are of great importance in the patient's quality of life. The most frequent are: dysuria, hematuria, urinary urgency, urinary frequency, bladder tenesmus, sexual dysfunction and abdominal pain. Scarneciu et $\mathrm{al}^{3}$ applied the Flanagan quality of life scale to 2,200 patients with USs, and found that their quality of life was affected as early as 7 days after the insertion.

The pathophysiology behind this symptomatology has not been fully understood; it is believed that it is related to the irritation of the bladder mucosa that is in contact with the distal portion of the US, as well as to urine reflux, and smooth muscle spasms. ${ }^{1-3}$

Due to the high frequency of the associated symptoms, multiple strategies have been developed with different drugs to prevent these adverse effects, such as analgesics, alpha adrenergic blockers and anticholinergics.

Alpha adrenergic blockers are the most used, mainly tamsulosin, which relaxes the ureter and increases urinary drainage. Kwon et $\mathrm{al}^{7}$, in a systematic review and meta-analysis, compared the use of alfuzosin against tamsulosin and placebo, and found that the symptoms were less severe in the group of patients managed with alpha blockers. In a meta-analysis by $\mathrm{He}$ et $\mathrm{al}^{8}$ of 16 controlled and randomized studies, the researchers found that alpha blockers generate an improvement in the symptoms associated with the insertion of a US, and that there is more evidence in favor of alfuzosin and terazosin than in favor of tamsulosin. 
Anticholinergics are widely used to prevent symptoms, and there are meta-analyses that justify their use. They are included in the American Urological Association (AUA) guidelines for the management of US discomfort, and their benefits have been extrapolated from patients with benign prostatic hypertrophy. $2,4,9$

Lee et al, ${ }^{10}$ in a randomized, double-blinded, and controlled study, compared the use of intrarectal belladonna suppositories against the use of placebo, with prior insertion of a US in 71 patients; they applied the American Urological Association Symptom Score (AUASS) scale before the procedure, the ureteral stent symptom questionnaire (USSQ), and the AUASS scale in the first and third postoperatory days, and after removing the US. They found that the use of belladonna decreased the symptoms associated with the insertion of a US.

Regarding the intravesical location of the distal end of the US, it has been found that when the stent crosses the middle line of the bladder the discomfort increases. ${ }^{11}$ Studies have been performed using stents impregnated with triclosan to try to reduce the symptoms, the risk of infection, and the incrustation. Mendez-Prost et a ${ }^{12}$ conducted a study with 20 randomized patients divided into one group that used nonimpregnated stents (control group) and another one that used stents impregnated with triclosan (Triumph, Boston Scientific Corp. Inc., Natick, MA, US) for short periods of time. Urine cultures were performed, and pain scales were applied to evaluate the symptoms. They found that in the group with the impregnated triclosan stents the symptoms decreased, but the risk of infection and incrustation did not.

Patient education regarding the symptoms associated with the insertion of a US is important; nonetheless, it is not a usual practice. Abt et al ${ }^{13}$ recommend high quality education for patients with a US, in order to help them understand their symptoms.

\section{Infection}

Bacterial colonization is inherent to the use of USs. The incidence of US colonization has been reported to be between 44 and $48 \%{ }^{14}$ García-Aparicio et al, ${ }^{14}$ in a retrospective study with 67 pediatric patients with 73 USs, reported a US colonization incidence of $58.9 \%$, and a $5.9 \%$ incidence of UTI. Pseudomona aeruginosa was the most frequent pathogen associated both to the US colonization and to the UTI. In patients with permanent use of US, bacterial colonization reaches an incidence of $100 \% .{ }^{1}$ Antibiotic prophylaxis is not recommended, and the antibiotic treatment is only indicated in patients with symptomatic UTI. ${ }^{1}$ Hashimoto et al ${ }^{15}$ performed two retrospective studies using antibiotic prophylaxis to prevent febrile episodes in patients with history of urinary derivation or reconstruction with JJ stents: in the first study, they compared the incidence of febrile episodes in 39 patients who received prophylaxis and 31 patients who did not (the chosen antimicrobial agent depended on the doctor's preferences); the incidence of febrile events was significantly lower in patients with prophylaxis ( $26 \%$ versus $51.6 \%$ ). In the second study, they gave prophylaxis to 75 patients before removing the stent, and they were divided into two groups: the first one was composed of 48 patients who received an oral fluoroquinolone $(200 \mathrm{mg}$ of norfloxacin or $200 \mathrm{mg}$ of levofloxacin), and the other group was composed of 27 patients who were given an intramuscular aminoglycoside (200 $\mathrm{mg}$ of isepamicin sulfate). The incidence of febrile episodes was similar in both groups (13\% for those with fluoroquinolone and $15 \%$ for the aminoglycoside group). Nevo et $\mathrm{al}^{16}$ determined the association between a positive urine culture and a positive US culture in 509 patients, finding positive urine cultures in $17.8 \%$ of the sample, and positive US cultures in $20.4 \%$; in $9.4 \%$ of the cases, both the urine and the US had positive cultures, but only $50 \%$ of these had the same pathogen isolated. The more frequent isolated pathogens were Escherichia coli and enterococci ( $38.5 \%$ and $18.4 \%$ respectively); $4.9 \%$ of the patients presented urinary sepsis, of which $84 \%$ had positive US cultures, and 59\% had positive urine cultures. They concluded that the risk of urinary sepsis is greater in female patients and in patients with a positive US culture.

Keheila et al ${ }^{17}$ performed a retrospective study with 150 patients to determine the fungal colonization of the US; the patients were divided into 3 groups according to the time of use of the US: the first group had been using the US from 0 to 20 days; the second, from 21 to 30 days; and the third, for more than 30 days. In group one, $70 \%$ of the patients presented a positive urine culture, and the main pathogen isolated was diphteroid (31\%). In group 2, 64\% had a positive urine culture, and the main pathogen was P. aeruginosa (30\%). In the last group, $58 \%$ had a positive urine culture, and the main pathogen isolated was candida (55\%). They concluded that the longer the use of a US, the greater the risk of fungi infection. Cirioni et al ${ }^{18}$ performed a study to determine the in vitro sensibility of azithromycin and ceftazidime to prevent the infection of the stent with P. aeruginosa, comparing its use with a monotherapy; they found that the combination of these two antibiotics prevented the formation of the biofilm. Kawahara et al, ${ }^{19}$ in a study with 29 patients with discolored stents, found that these patients have a greater risk of presenting a positive urine culture, and higher urine $\mathrm{pH}$. The reason why stents lose color is unknown to this date.

\section{Incrustation}

The incrustation of the stent is considered a severe complication that requires a multimodal approach. It is mainly associated with a forgotten or retained US. ${ }^{20}$ The most important risk factor for a US to incrust is a long indwelling time (in general, longer than 6 months). According to elFaqih et al, ${ }^{21}$ the rate of incrustation varies from 9.2 to $76.3 \%$ depending on the time of use of the stent ( 6 weeks and more than 12 weeks respectively).

Other associated factors are urinary sepsis, history of lithiasis, chemotherapy, pregnancy, chronic renal disease, and metabolic or congenital diseases. ${ }^{20,22}$ The best way to prevent a US from incrustation, is to remove it as soon as it is no longer necessary, and to change the US every two to four months if the patient requires permanent use. ${ }^{20}$

The treatment for incrustation is endourological, but requires experience because there is no consensus or an algorithm to manage this complication. Ahallal et $\mathrm{al}^{20}$ consider 
that the best management for a small percentage of incrusted USs, in patients with good renal function, is the extracorporeal lithotripsy (EL), which enables the spontaneous release of small fragments. Adanur et al, ${ }^{22}$ in a case series of 44 patients with incrusted USs, initiated the management with EL in 18 of them: in 5 of the patients the US removal could be easily performed via direct cystoscopy; the rest of them required other endourological procedures for the extraction of the US. Five cases required cystolithotripsy due to the incrustation of the distal part of the US.

Arenas et $\mathrm{al}^{23}$ described the kidney, ureter, bladder (KUB) scale based on the level of incrustation of the stent in the kidney, ureter and bladder, which enables the urologist to identify the complexity of the surgery to remove the stent.

\section{Migration}

Even though the US must be self-holding, there is a chance of proximal or distal migration. The proximal migration towards the ureter has an incidence of 1 to $8 \%,{ }^{1}$ and it could be due to the selection of a very large stent. Ureteral stents have an intravesical distal cord that enables an easier endoscopic retrieval of the stent, but this cord is associated with the migration of the catheter. Althaus et al, ${ }^{24}$ in a retrospective study with 512 patients taken into ureteroscopy, found that in $15 \%$ of the patients with a US the distal cord migrated, especially in female patients.

\section{Forgotten US}

A forgotten US has a multifactorial etiology: forgetfulness of the patient, lack of follow-up due to problems in the health care system, or lack of communication between the urologist and the patient. It is estimated that up to $12 \%$ of USs are forgotten. ${ }^{25}$

Abandoning a US is an important health issue that is associated with an increase in costs, due to the necessary procedures that the diagnosis requires, such as the retrieval of the stent, and the management of the associated complications (UTI, urinary sepsis, incrustation, loss of renal function, among others). ${ }^{22,26}$ Pais et $\mathrm{al}^{27}$ performed a systematic review and meta-analysis of 17 papers, and found that forgotten JJ stents increase the number of unplanned emergency room visits.

There are no guidelines or algorithms for the management of these forgotten USs, but a few alternatives have been proposed to define a better approach. Adanur et $\mathrm{al}^{22}$ described 54 patients with forgotten stents that were managed with endourological techniques, preventing renal function loss; only one patient required nephrectomy due to a nonfunctional kidney secondary to the US.

Due to the fact that a forgotten US is associated with incrustation, in many cases this complication must be managed first. Given the importance of the incidence and complications associated with a forgotten US, many techniques that decrease the risk of forgetting the US on the part of the patients and the health care centers have been developed. Larkin et $\mathrm{al}^{28}$ described an electronic and computerized method with a Microsoft Excel (Microsoft Corporation, Redmond WA, US) database in which the urologist must register the patients who require the insertion of a US, and the date of insertion and extraction. It reminds the urologist when the US should be removed. The method enabled the recruitment of all (100\%) inserted stents. Molina et $\mathrm{al}^{25}$ developed a smart phone app (called "Stent Tracker"), in a multicenter study with 194 patients, which enabled a better control of the patients; only one of them could not be controlled due to communication issues. Baumgarten et $\mathrm{al}^{29}$ developed a database with a multidisciplinary group that alerted the urologist and the patients that the US should be removed.

\section{J] stent use in lithiasis}

The use of USs in lithiasis is controversial. Multiples studies have identified that the use of a stent does not decrease the free lithiasis rate or the number of emergency room visits, and, likewise, increases the discomfort, the presence of hematuria, bladder irritation and UTI; thus, the use of USs after a noncomplicated episode of lithiasis is not advised. ${ }^{30-32}$ Some variables play an important role in the insertion of the US; it seems that the size of the stone could be an important factor. Picozzi et $\mathrm{al}^{32}$ found that the diameter of the stone does not affect the rate of insertion of a US. You et $\mathrm{al}^{33}$ wanted to identify the necessity of insertion of a US after performing a laparoscopic ureterolithotomy, and found that it was not necessary due to the fact that, in the majority of the cases, there is no urinary leak or ureteral stricture after the surgery.

\section{Utility of US in cancer and Resonance Metallic Ureteral Stent}

The symptoms associated with the decrease in the ureteral lumen due to malignancy are a clear indication for the insertion of a US. Nonetheless, this is a very controversial topic. Chow et $\mathrm{al}^{36}$ studied 42 patients with malignant ureteral obstruction, in whom a polymeric US was initially inserted, and later on was replaced with a Resonance Metallic Ureteral Stent (Cook Medical LLC, Bloomington, IN, US).Tthey found that the metallic US had higher rates of duration, and should be considered as a first treatment option in these patients. ${ }^{34}$ However, it has been demonstrated that up to $35 \%$ of these metallic stents fail, mainly in patients with wallinvading prostate cancer; the most common signs of failure are hydronephrosis and an increase in creatinine levels. ${ }^{35}$ Radiologic findings enable the clinician to predict the risk of failure of a US. Chow et $a^{36}$ inserted Resonance Metallic Ureteral Stents in 74 patients with urinary tract obstruction, and found that the obstruction of the abdominal ureter and lymphatic metastasis are independent risk factors for the failure of the US. Wang et $\mathrm{al}^{37}$ studied 164 patients, and found that the Eastern Cooperative Oncology Group performance status (ECOG-PS) grade, the hydronephrosis grade, and the invasion of the bladder are independent factors for the failure of the US; thus, the ambulatory retrograde insertion of the US is not suggested in patients with hydronephrosis $>30 \mathrm{~mm}$, ECOG PS $\geq 2$, or in patients with vesical invasion identified by computed tomography (CT) or magnetic resonance imaging (MRI) scans.

Why do USs fail in cases of cancer? In a person with no medical history, the urine flows because of muscular coordination; when a US is inserted, the peristaltic activity decreases, 
increasing the intrapelvic pressure, and enabling the production of mucus, which can obstruct the US. Nonetheless, the urine can continue to flow outside the lumen of the US. When malignancy exists, this extra luminal flow of urine is limited by the extrinsic compression caused by the tumor. ${ }^{38,39}$ Metallic USs have greater strength, tensile force, and resistance to exterior compression when compared with non-metallic stents, thus being more durable. ${ }^{39,40}$ The durability of a metallic US is greater in patients with non-malignant obstructions, and metallic USs have been reported by Wang et $\mathrm{a}^{41}$ to last up to nine months, and up to five years by Kadlec et al. ${ }^{42}$ Insertion of a metallic US is recommended in patients that have a greater risk of failure, such as those with malignant obstructions. ${ }^{43}$

Despite the durability of the metallic USs, they can present complications in up to half of the patients, especially in patients with advanced stages of cancer. The complications include: abdominal pain, persistent hematuria, severe dysuria, and insufficient drainage. ${ }^{44}$ Nonetheless, other studies report that the level of failure is the same both for the benign and malignant etiologies of the ureteral obstruction. ${ }^{45}$

There are different types of metallic USs. Lee and $\mathrm{Kim}^{46}$ compared two types of metallic stents: one with a spiral form that expanded with heat (Memokath 051, PNN Medical, Kvistgaard, Denmark), and one self-expandable stent (UVENTA, Taewoong Medical, Gimpo-si, Gyeonggi-do, South Korea); they noted that the UVENTA stent had greater rates of success, and could be used for both benign and malignant pathologies. The rate of complications of both stents is the same.

\section{Novelties in the use of ureteral stents}

Multiple studies have been conducted with the goal of improving the quality of USs, and despite the fact that most of them are experimental, they give the urological community a hint of the future of USs. Huynh et $\mathrm{a}^{47}$ proposed a US that illuminates, enabling an easier identification of the ureter during colonic surgery, thus avoiding a possible injury to the ureter. Soria et $\mathrm{al}^{48}$ developed and tested an anti-reflux US in healthy pigs with ultrasonography and excretory urography before inserting a $3 \mathrm{Fr}$ US, and, after removing it, they found that the US had effectively decreased the vesicoureteral reflux.

One of the most studied and controversial topics is the development of biodegradable USs. Li et $\mathrm{al}^{49}$ proposed a biodegradable model using poli-L-lactic acid and poli-DLlactic acid in dogs, and they had good results. Barros et $\mathrm{al}^{50}$ developed a model of US based on jelly, which started to degrade after 3 days of its insertion; it was radio-opaque (even when wet), and non-cytotoxic. They developed a totally functioning model, but it was not tested in humans. The same author, in a subsequent study, developed a biodegradable US capable of instilling drugs, with emphasis on paclitaxel, epirubicin, doxorubicin and gemcitabine; this US was exposed to a line of cancer cells in vitro, and the researchers were able to identify a significant decrease in the number of cancer cells. ${ }^{51}$

It is assumed that preventing the formation of biofilm in the stent could decrease the risk of associated infections, thus enabling the avoidance of the use of prophylactic antibiotics. Rosman et al ${ }^{52}$ invented a US based on resistant biofilm jelly, achieving a decrease in the number of bacteria.

\section{Discussion}

Advances in the use of $\mathrm{JJ}$ stents were accomplished in recent years, which is why we believe it is pertinent to review this topic. We focused our revision in the management and prevention of the symptoms and complications associated with the use of JJ stents.

The main symptoms associated are dysuria, hematuria, urinary frequency, sexual dysfunction and abdominal pain, with a high negative impact on the quality of life. There are multiple studies that have tried to use alpha antagonists for the management of these symptoms, because of the fact that these drugs decrease urine reflux. ${ }^{1,7,8}$ These symptoms are worsened when the distal part of the US crosses the middle line of the bladder. ${ }^{1}$ Anticholinergics are recommended in the AUA guidelines to decrease the symptomatology, but there is no strong evidence for their use. ${ }^{4}$

The incidence of US colonization has been reported range from 44 to $48 \%$, and $P$. aeruginosa is the most prevalent pathogen reported; ${ }^{14}$ this colonization directly relates to the risk of urinary sepsis. Patients that use stents for longer than 30 days are at a greater risk of infection by candida. ${ }^{17}$

A strict follow-up of the patients with USs must be performed: up to $12 \%$ of stents are forgotten, ${ }^{25}$ and, as a consequence, the patient could end up being submitted to a nephrectomy or with an incrusted US. ${ }^{22}$ This can be prevented by changing the stent every 2 to 4 months, ${ }^{1,20}$ and by performing a strict follow-up of these patients; there are various studies that propose methods to achieve this.

Regarding the use of US in lithiasis, using them after a noncomplicated episode of lithiasis is not recommended. ${ }^{30-32}$

Metallic USs have greater strength, tensile force and resistance to external compression when compared with regular ones; ${ }^{39}$ they are cost-effective and useful in both benign and malignant obstructions. ${ }^{41}$ Their complications are more common in patients diagnosed with cancer; 38,39 nevertheless, they are still preferred to manage malignant obstructions; ${ }^{34}$ there is a risk of failure of up to $35 \%,{ }^{35}$ especially in patients with obstruction of the wall of the abdominal ureter, lymphatic metastasis, high ECOG-PS grades, and severe preoperative hydronephrosis. ${ }^{36-38}$

There is a great number of studies that intend to improve USs. The most promising ones are those of biodegradables USs, which start to degrade after 3 days, are radio-opaque and non-cytotoxic. ${ }^{50}$ Other novelties are USs that are luminous, anti-reflux, and biofilm-resistant. ${ }^{52}$ They could also be used to instill chemotherapy for the management of upper tract urothelial cancer. ${ }^{51}$

\section{Conclusions}

JJ stents remain very useful tools in the daily urologic practice, and they are widely used in the management of ureteral obstruction (both benign and malignant). Nonetheless, they are not exempt from having secondary effects associated with their insertion, such as infection, irritative symptoms, and the risk of incrustation. Even though we still do not have the ideal US, there have been many important 
developments that help decrease the associated risks caused by their use.

\section{Funding}

The authors have none to declare.

\section{Conflict of Interests}

The authors have none to declare.

\section{References}

1 Tailly T, Denstedt J. Fundamentals of Urinary Tract Drainage. In: Wein, Alan J., MD, PhD (HON), FACS; Kavoussi, Louis R., MD, MBA; Partin, Alan W., MD, PhD; Peters, Craig AM, ed. Campbell's Urology. 11th ed. Philadelphia: Elsevier; 2016:1119-1135

2 Joshi HB, Newns N, Stainthorpe A, MacDonagh RP, Keeley FX Jr, Timoney AG. Ureteral stent symptom questionnaire: development and validation of a multidimensional quality of life measure. J Urol 2003;169(03):1060-1064 Doi: 10.1097/01.ju.00000 49198.53424.1d

3 Scarneciu I, Lupu S, Pricop C, Scarneciu C. Morbidity and impact on quality of life in patients with indwelling ureteral stents: A 10year clinical experience. Pak J Med Sci 2015;31(03):522-526 Doi: 10.12669/pjms.313.6759

4 Sivalingam S, Monga M. Management of Ureteral Stent Discomfort in Contemporary Urology Practice. Urol Pract 2014;1(03): 141-145 Doi: 10.1016/j.urpr.2014.06.001

5 Soria F, Morcillo E, Serrano A, et al. Preliminary Assessment of a New Antireflux Ureteral Stent Design in Swine Model. Urology 2015;86(02):417-422 Doi: 10.1016/j.urology.2015.05.020

6 Alfredo ML. Catéter ureteral olvidado.Urol Colomb 2007;16:139-148

7 Kwon JK, Cho KS, Oh CK, et al. The beneficial effect of alphablockers for ureteral stent-related discomfort: systematic review and network meta-analysis for alfuzosin versus tamsulosin versus placebo. BMC Urol 2015;15:55 Doi: 10.1186/s12894-015-0050-5

8 He F, Man LB, Li GZ, Liu N. Efficacy of $\alpha$-blocker in improving ureteral stent-related symptoms: a meta-analysis of both direct and indirect comparison. Drug Des Devel Ther 2016;10:1783-1793 Doi: 10.2147/DDDT.S103195

9 Kuyumcuoglu U, Eryildirim B, Tuncer M, Faydaci G, Tarhan F, Ozgül A. Effectiveness of medical treatment in overcoming the ureteral double-J stent related symptoms. Can Urol Assoc J 2012;6 (06):E234-E237 Doi: 10.5489/cuaj.10143

10 Lee FC, Holt SK, Hsi RS, Haynes B, Harper JD. Preoperative Belladonna and Opium Suppository for Ureteral Stent Pain: a Randomized, Double-Blinded, Placebo Controlled Study. Urology 2017; 100: 27-32

11 Abt D, Mordasini L, Warzinek E, et al. Is intravesical stent position a predictor of associated morbidity? Korean J Urol 2015;56(05): 370-378 Doi: 10.4111/kju.2015.56.5.370

12 Mendez-Probst CE, Goneau LW, MacDonald KW, et al. The use of triclosan eluting stents effectively reduces ureteral stent symptoms: a prospective randomized trial. BJU Int 2012;110(05): 749-754 Doi: 10.1111/j.1464-410X.2011.10903.x

13 Abt D, Warzinek E, Schmid HP, Haile SR, Engeler DS. Influence of patient education on morbidity caused by ureteral stents. Int J Urol 2015;22(07):679-683 Doi: 10.1111/iju.12782

14 García-Aparicio L, Blázquez-Gómez E, Martin O, Krauel L, De Haro I, Rodó J. Bacterial characteristics and clinical significance of ureteral double-J stents in children. Actas Urol Esp 2015;39 (01):53-56 Doi: 10.1016/j.acuro.2014.04.008

15 Hashimoto J, Takahashi S, Kurimura Y, Takeyama K, Kunishima Y, Tsukamoto T. Clinical relevance of single administration of prophylactic antimicrobial agents against febrile events after removal of ureteral stents for patients with urinary diversion or reconstruction. Int J Urol 2010;17(02):163-166 Doi: 10.1111/j.1442-2042. 2009.02432.x

16 Nevo A, Mano R, Schreter E, Lifshitz DA. Clinical implications of stent culture in patients with indwelling ureteral stents prior to ureteroscopy.JUrol 2017;198(01):116-121 Doi: 10.1016/j.juro.2017.01.064

17 Keheila M, Chan C, Cheriyan S, et al. Increasing Fungal Colonization With Increased Duration of Ureteral Stents. J Urol 2016;195 (04):e1077 Doi: 10.1016/j.juro.2016.02.2153

18 Cirioni O, Ghiselli R, Silvestri C, et al. Effect of the combination of clarithromycin and amikacin on Pseudomonas aeruginosa biofilm in an animal model of ureteral stent infection. J Antimicrob Chemother 2011;66(06):1318-1323 Doi: 10.1093/jac/dkr107

19 Kawahara T, Miyamoto H, Ito H, et al. Discolored ureteral stents: findings in urinalysis and urine culture. PLoS One 2015;10(04): e0122984 Doi: 10.1371/journal.pone.0122984

20 Ahallal Y, Khallouk A, El Fassi MJ, Farih MH. Risk factor analysis and management of ureteral double-j stent complications. Rev Urol 2010;12(2-3):e147-e151 Doi: 10.3909/riu0447

21 el-Faqih SR, Shamsuddin AB, Chakrabarti A, et al. Polyurethane internal ureteral stents in treatment of stone patients: morbidity related to indwelling times. J Urol 1991;146(06):1487-1491

22 Adanur S, Ozkaya F. Challenges in treatment and diagnosis of forgotten/encrusted double-J ureteral stents: the largest singlecenter experience. Ren Fail 2016;38(06):920-926 Doi: 10.3109/ 0886022X.2016.1172928

23 Arenas JL, Shen JK, Keheila M, et al. Kidney, Ureter, and Bladder (KUB): A Novel Grading System for Encrusted Ureteral Stents. Urology 2016;97:51-55 Doi: 10.1016/j.urology.2016.06.050

24 Althaus AB, Li K, Pattison E, Eisner B, Pais V, Steinberg P. Rate of dislodgment of ureteral stents when using an extraction string after endoscopic urological surgery. J Urol 2015;193(06):2011-2014 Doi: 10.1016/j.juro.2014.12.087

25 Molina WR, Donalisio da Silva R, Kenny MC, et al. Mp08-14 Stentracker: a Smartphone Application for the Prevention of “Forgotten" Retained Ureteral Stents (Rus). J Urol 2016;195(04): e90 Doi: 10.1016/j.juro.2016.02.2259

26 Dakkak Y, Janane A, Ould-Ismail T, Ghadouane M, Ameur A, Abbar M. Management of encrusted ureteral stents. Afr J Urol 2012;18 (03):131-134 Doi: 10.1016/j.afju.2012.08.013

27 Pais VM Jr, Smith RE, Stedina EA, Rissman CM. Does Omission of Ureteral Stents Increase Risk of Unplanned Return Visit? A Systematic Review and Meta-Analysis. J Urol 2016;196(05): 1458-1466 Doi: 10.1016/j.juro.2016.05.109

28 Larkin S, Preston D. Where are the Stents? A Computerized Tracking System to Eliminate the Forgotten Ureteral Stent. Urol Pract 2015;2(03):106-108 Doi: 10.1016/j.urpr.2014.09.010

29 Baumgarten AC, Rydberg MG, Bates JN, Teigland CM, Roy OP. Reducing the Incidence of Retained Double-J Ureteral Stents: A Multidisciplinary Approach. Urol Pract 2016;3(05):325-331 Doi: 10.1016/j.urpr.2015.10.005

30 Pengfei S, Yutao L, Jie Y, et al. The results of ureteral stenting after ureteroscopic lithotripsy for ureteral calculi: a systematic review and meta-analysis. J Urol 2011;186(05):1904-1909 Doi: 10.1016/ j.juro.2011.06.066

31 Wang H, Man L, Li G, Huang G, Liu N, Wang J. Meta-Analysis of Stenting versus Non-Stenting for the Treatment of Ureteral Stones. PLoS One 2017;12(01):e0167670 Doi: 10.1371/journal.pone.0167670

32 Picozzi SCM, Ricci C, Stubinski R, et al. Is stone diameter a variable in the decision process of employing a ureteral stent in patients undergoing uncomplicated ureterorenoscopy and associated intracorporeal lithotripsy? World J Urol 2013;31(06):1617-1625 Doi: 10.1007/s00345-013-1046-y

33 You JH, Kim YG, Kim MK. Should we place ureteral stents in retroperitoneal laparoscopic ureterolithotomy?: Consideration of surgical techniques and complications Korean J Urol 2014;55(08): 511-514 Doi: 10.4111/kju.2014.55.8.511 
34 Chow PM, Chiang IN, Chen CY, et al. Malignant ureteral obstruction: Functional duration of metallic versus polymeric ureteral stents. PLoS One 2015;10(08):e0135566 Doi: 10.1371/journal.pone.0135566

35 Goldsmith ZG, Wang AJ, Bañez LL, et al. Outcomes of metallic stents for malignant ureteral obstruction. J Urol 2012;188(03): 851-855 Doi: 10.1016/j.juro.2012.04.113

36 Chow PM, Hsu JS, Wang SM, Yu HJ, Pu YS, Liu KL. Metallic ureteral stents in malignant ureteral obstruction: short-term results and radiological features predicting stent failure in patients with nonurological malignancies. World J Urol 2014;32(03):729-736 Doi: 10.1007/s00345-013-1143-y

37 Wang JY, Zhang HL, Zhu Y, Qin XJ, Dai BO, Ye DW. Predicting the failure of retrograde ureteral stent insertion for managing malignant ureteral obstruction in outpatients. Oncol Lett 2016;11(01): 879-883 Doi: 10.3892/ol.2015.3961

38 Kamiyama Y, Matsuura S, Kato M, et al. Stent failure in the management of malignant extrinsic ureteral obstruction: risk factors. Int J Urol 2011;18(05):379-382 Doi: 10.1111/j.14422042.2011.02731.x

39 Elsamra SE, Leavitt DA, Motato HA, et al. Stenting for malignant ureteral obstruction: Tandem, metal or metal-mesh stents. Int J Urol 2015;22(07):629-636 Doi: 10.1111/iju.12795

40 Chung HH, Kim MD, Won JY, et al. Multicenter experience of the newly designed covered metallic ureteral stent for malignant ureteral occlusion: comparison with double J stent insertion. Cardiovasc Intervent Radiol 2014;37(02):463-470 Doi: 10.1007/s00270-0130675-2

41 Wang HJ, Lee TY, Luo HL, et al. Application of resonance metallic stents for ureteral obstruction. BJU Int 2011;108(03):428-432 Doi: 10.1111/j.1464-410X.2010.09842.x

42 Kadlec AO, Ellimoottil CS, Greco KA, Turk TM. Five-year experience with metallic stents for chronic ureteral obstruction. J Urol 2013;190(03):937-941 Doi: 10.1016/j.juro.2013.02.070

$43 \mathrm{Kim} \mathrm{KH}$, Cho KS, Ham WS, Hong SJ, Han KS. Early Application of Permanent Metallic Mesh Stent in Substitution for Temporary Polymeric Ureteral Stent Reduces Unnecessary Ureteral Proce- dures in Patients With Malignant Ureteral Obstruction. Urology 2015;86(03):459-464 Doi: 10.1016/j.urology.2015.06.021

44 Kallidonis PS, Georgiopoulos IS, Kyriazis ID, Kontogiannis S, AlAown AM, Liatsikos EN. The full metallic double-pigtail ureteral stent: Review of the clinical outcome and current status. Indian J Urol 2015;31(01):8-14 Doi: 10.4103/0970-1591.134232

45 Kadlec AO, Ellimoottil CS, Greco KA, Turk TM. Five-year experience with metallic stents for chronic ureteral obstruction. J Urol 2013;190(03):937-941 Doi: 10.1016/j.juro.2013.02.070

46 Lee JN, Kim BS. Comparison of efficacy and bladder irritation symptoms among three different ureteral stents: a double-blind, prospective, randomized controlled trial. Scand J Urol 2015;49 (03):237-241 Doi: 10.3109/21681805.2014.981205

47 Huynh D, Hockman L, Trulson J, Wakefield M. Advantages and Technical Challenges of Lighted Ureteral Stents During Laparoscopic Bowel Surgery. J Urol 2015;193(04):e474 Doi: 10.1016/j. juro.2015.02.1437

48 Soria F, Morcillo E, Serrano A, et al. Preliminary Assessment of a New Antireflux Ureteral Stent Design in Swine Model. Urology 2015;86(02):417-422 Doi: 10.1016/j.urology.2015.05.020

$49 \mathrm{Li} \mathrm{G}$, Wang ZX, Fu WJ, et al. Introduction to biodegradable polylactic acid ureteral stent application for treatment of ureteral war injury. BJU Int 2011;108(06):901-906 Doi: 10.1111/j.1464410X.2010.09992.x

50 Barros AA, Oliveira C, Lima E, Duarte ARC, Reis RL. Gelatinbased biodegradable ureteral stents with enhanced mechanical properties. Appl Mater Today 2016;5:9-18 Doi: 10.1016/j.ap mt.2016.07.006

51 Barros AA, Browne S, Oliveira C, et al. Drug-eluting biodegradable ureteral stent: New approach for urothelial tumors of upper urinary tract cancer. Int J Pharm 2016;513(1-2):227-237 Doi: 10.1016/j.ijpharm.2016.08.061

52 Rosman BM, Barbosa JA, Cendron M, Retik AB, Nguyen HT, Cilento BG. 862 Development and Evaluation of a Novel Gel-Based Ureteral Stent With Biofilm Resistant Characteristics. J Urol 2012;187(04):e352 Doi: 10.1016/j.juro.2012.02.955 